\title{
Digital Information and Value: A Response to Jakob Rigi
}

\author{
Bryan J. Parkhurst \\ Oberlin College, Oberlin, OH, USA, bparkhur@oberlin.edu
}

\begin{abstract}
In a series of recent articles, Jakob Rigi has formulated an articulate and sophisticated Marxian view about the relationship between digital production and value theory. Anyone interested in the economic dynamics of FAMGA (Facebook, Apple, Microsoft, Google and Amazon) needs to come to terms with the position Rigi stakes out. In this article, I challenge Rigi's thesis that profits from the sale of digital information (DI) constitute rent. I do so by calling into question his conclusions concerning the valuelessness of DI. After summarising Rigi's core position and sketching out its entailments, I make the case that (1) Rigi's assertions about the intrinsic valuelessness of DI are not supported by the model of production he invokes; that (2) Rigi's valuelessness argument in fact presupposes that DI has value; that (3) far from furnishing evidence that DI is valueless and therefore a source of rent income, as Rigi holds, the existence of the intellectual property regime is precisely what allows $\mathrm{DI}$ to act as a congealment of value (i.e. labour time) in commodity form; and that (4) Rigi misapplies Marx's notion of reproduction to the sale/copy/distribution of DI. I offer this critique as an invitation for us to rethink, from a Marxian perspective, the status of the digital economy within the order of global capitalist value production.
\end{abstract}

Keywords: value, digital information, Marx, Rigi, labour

Acknowledgement: I would like to thank Dave Beech, Jarek Ervin, Ben Laude, and audience members at Historical Materialism London (2017) for criticisms and suggestions for improvement.

\section{Digital Information: Contra the Labour Theory of Value}

It has become commonplace to announce that trends in contemporary capitalist production render Marx's theory of value obsolete. Prominent among such trends are those ranged under the headings of 'digital production', 'info-capitalism', the 'cybereconomy', and 'cognitive capitalism'. One simplistic line of reasoning that leads to the summary rejection of the labour theory of value (LTV) goes like this: since digital information (DI) - i.e. "forms of perception or cognition such as codes, concepts, formulas, data, design, images, software, language, etc., that can be digitally and infinitely reproduced" (Rigi 2014a, 909) - can be copied and distributed with almost no expenditure of labour, and since making and selling digital content can be a valuable source of profit for capitalist firms, it follows that socially-necessary labour time is not what grounds value. To spell this out a bit more, if DI is 'immaterial' and infinitely multiplicable at no cost, and if, correlatively, its non-physical nature prohibits it from acting as a finite, tangible commodity-object in which a determinate amount labour-power is concretely embodied, and if $\mathrm{DI}$ is nevertheless valuable, then we can conclude that the value of commodities is not a function of the amount of waged labour time embodied in them, and that "the factory regime of time and related to that the Marxian law of value are passé" (Rigi 2015, 189). An entailment of this is that Marx is wrong to understand capitalist exploitation as consisting in the appropriation of surplus value (i.e. the 
confiscation of the difference between the value created by the number of hours actually worked and the value of the wage bill): "In the paradigm of immaterial production, the theory of value cannot be considered in terms of measured quantities of time, so exploitation cannot be understood in these terms" (Hardt and Negri 2004, 150).

\section{A Rejoinder from Rigi}

Several of Jakob Rigi's recent publications (2012; 2013; 2014a; 2014b; 2015; Rigi and Prey 2015) show how conceptual resources drawn from Marx allow for an easy rebuttal of the above argument. Rigi also presents a positive counterproposal to the argument's conclusion. Here I focus primarily on positions set out in Rigi (2014a), but I draw from other texts occasionally.

\subsection{The Rebuttal}

Rigi correctly reminds us that within the framework of Marx's value theory, the fact that the creation and sale of $\mathrm{DI}$ is a source of profit for capitalist firms does not imply that DI possesses value (in Marx's technical sense of "value": embodied labour-time). Indeed, the idea that amassing profit and producing value are potentially distinct and separable activities is one of the core tenets of Marxian economics. According to Marx's account of cross-sector averaging of the profit rate, capital's habitual gravitation toward high-profit sectors, which results in an excess of investment and output in those sectors that serves to diminish their profitability, causes a system-wide evening-out of the rate of return on investment. Owing to this levelling effect, the total pot of surplus value gets divided up amongst capitalists according to cost price (c+v) rather than labour expenses (v) alone. Rigi, summing up Marx's analysis, states that

Capital flows from branches with high organic compositions to branches with low organic compositions. Consequently, the supply of commodities in the first branch decreases and their prices increase. This increases their profits. The reverse happens in the second branch. This continues until a general rate of profit, which is equal to the total surplus-value divided by the total social capital, stabilizes so that a given capital earns the same amount of average profit regardless of the branch in which it is invested $(2015,196){ }^{1}$

So even capitalists who produce and sell commodities for which $v=0$ will tend to receive the average rate of profit, though they produce no surplus value (by hypothesis, since labour, and labour alone, can create value). Rigi $(2015,192)$ notes: "As labour (variable capital) is the source of new value, a fully automated production unit does not produce any new value. It only transfers the value of constant capital to the product." Yet zero-labour goods and services - think of the fully-automated, unattended car washes that are common in suburban America - can still be a source of revenue. Hence the fact that DI can be made cheap and sold dear is not in and of itself a reason to think that DI is valuable; and the fact that the copying and distributing of $\mathrm{DI}$ is a labourless affair (if it is) is not a reason to jettison the LTV. To encapsulate the rebuttal even more succinctly: (1) for Marx, value isn't the same as price, and (2) things with no value can have prices, so (3) the fact that DI has a price does not show that it has

${ }^{1}$ A corollary is that some capitalists are parasitic on other capitalists: "Capitalists who invest in automated production or in the production of cognitive forms make money (profits or rents) that is value. As they themselves do not produce value they extract it in forms of profit and rent from sectors that produce it" (Rigi 2015, 196). 
value, so (4) the fact that DI contains little or no congealed labour time does not count against, much less decisively disprove, the LTV.

\subsection{The Counterproposal}

Marx's account of average profit rates tells us why we don't have to believe, on the strength of arguments about the immaterial nature of DI, that the LTV is false. Rigi's positive counterproposal to the anti-LTV conclusion tells us what we ought to believe instead, to wit: that given the truth of the LTV, since no labour is embodied in DI, it follows that $\mathrm{DI}$ is valueless.

Like Rigi, I accept the LTV and believe that "distribution of surplus value is the core aspect of contemporary capitalism" (Rigi 2014a, 911). However, I do not think that Rigi gives us compelling reasons for arriving at the verdict that $\mathrm{DI}$ is inherently valueless. After saying something about why it is important to interrogate Rigi's arguments, I spend the rest of this article pinpointing where I think they go wrong. I do not attempt to defend the positive claim that some or all DI production is in fact value-productive (although I think it might be); my more modest goal is to show that Rigi has not offered probative considerations in favour of believing that all DI production is, by its very nature, non-value-productive. For all we know, DI has value.

\section{Rigi's Position and its Implications}

Here is a statement from Rigi about why DI is valueless:

The reason why the value of cognitive forms [such as DI] tends to zero is that once produced, [this form of] knowledge can be reproduced at almost negligible time and costs [...] As Marx argues: "...the value of commodities is not determined by the labour time originally taken by their production, but rather by the labour time that their reproduction takes ..." $(2015,193){ }^{2}$

${ }^{2}$ According to Rigi 2014a (912), "Marx expresses the idea that information has a negligible value in [two] passages". One of them, from Marx's Theories of Surplus Value, states that "the product of mental labour - science - always stands far below its value, because the labour-time needed to reproduce it has no relation at all to the labour-time required for its original production. For example, a schoolboy can learn the binomial theorem in an hour" (Marx 1969, 353). The other, from the first volume of Capital, states that "once discovered, the law of the deviation of the magnetic needle in the field of an electric current, or the law of the magnetisation of iron, around which an electric current circulates, cost never a penny. But the exploitation of these laws for the purposes of telegraphy, etc., necessitates a costly and extensive apparatus" (Marx 1976, 508). In a footnote to the remark in Capital, Marx continues his train of thought: "Science, generally speaking, costs the capitalist nothing, a fact that by no means hinders him from exploiting it" (Marx 1976, $508 \mathrm{n} 23$ ). These passages must be taken with a grain of salt. In the first passage, Marx suggests that the value of the product of science - information - is high compared to where the product "stands" (Das Produkt [...] steht immer tief unter ihrem Wert), which seems to mean that its cost is significantly below its value. But this is just the opposite of expressing "the idea that information has a negligible value" (Rigi 2014a, 912). More importantly, though, it is unclear how cost and value could literally pertain to the example. The binomial theorem was certainly not 'produced' by abstract socially necessary labour time performed by wage labourers at the behest of capitalists (it was stated by Newton in 1676 and proved by John Colson in 1736), and when a student learns it, this is not a literal instantiation of capitalist reproduction of a commodity (even if the educational enterprise is for-profit). In the second passage, Marx makes a claim about the cost of scientific laws (which are a form of information, on Rigi's definition), which Marx says 
This thesis leads Rigi to advance a number of bold hypotheses about how DI functions in the world economy:

- Rigi holds that profit gained from the sale of DI is a form of rent extraction (Rigi 2014a). Information, like land, is both valueless (since its price "tends toward 0" (Rigi 2014a)) and scarce (artificially, due to intellectual property laws), and the owners of information add no surplus value to the global total. But they do withdraw value from the common pot by receiving remuneration for leasing this valueless item to others. This parallels the activities of the rentier class.

- Massive growth in the information sector (post-1980) has been a major factor in the elevation of the global organic composition of capital (since DI production requires negligible variable capital but non-negligible constant capital), and thus has served to decrease the global rate of profit:

The expansion of the role of information in the economy undermines the general rate of profit of the total social capital in two ways. First, the rentier capital that produces and sells information receives a considerable amount of the total social surplus value in the form of rent without itself contributing to this total surplus value. Second, the capital which is invested in automated and semi-automated informationintensive manufacturing and services, if it produces surplus value at all (the fully automated firms do not produce surplus value), contributes far less surplus value to the total social surplus value than the amount of surplus value that it receives back as profit from this total fund (Rigi 2014a, 929).

- DI production is a cause of uneven development and is a form of economic imperialism. Because of profit rate averaging, DI profits are made at the expense of highly surplus-value-generating, labour-intensive agricultural and extractive industries, largely located in the Global South.

Research and development and the production of advanced technologies and services have overwhelmingly, though not exclusively, been concentrated in a handful of advanced capitalist countries. On the other hand, less advanced manufacturing and agriculture has dramatically expanded in Third World countries. Thus, a major portion of the total global surplus value is produced outside the territory of advanced capitalism. Advanced capitalist countries suck a significant share of this [peripheral] surplus value in the forms of surplus profit and rent-tribute by means of trade secrets and intellectual property. In this way the concomitant enclosure of information and extraction of surplus value underpin the information dimension of imperialism (Rigi 2014a, 933).

- The elevated economic salience of DI points to the accelerating obsolescence of value as a goal and regulator of production.

is zero, but he says nothing about how the laws' value compares to their cost. This again contradicts Rigi, for the principal tenet of Rigi (2014a) is that information can be quite costly (under the intellectual property regime) even though it is intrinsically valueless. Marx's remarks do not at all corroborate Rigi's position on DI and value. 
That the value of information tends towards zero while information technologies constitute the vanguard forces of production of our time means that the law of value is obsolete. However, in spite of its historical redundancy this law still dominates the world economy. This domination suffocates the expansion of commons of information on the one hand and destroys nature on the other. This unprecedentedly heightened contradiction between the forces of productions (humans, information and nature) and relations of production (the law of value) is a call for abolishing of capitalism (Rigi 2014a, 933).

This all sounds quite momentous. If it were accurate, it would have big implications for how to think about, and what to do about, capitalist crisis. Allegedly, a systemic proneness to crisis is exacerbated by the special immaterial nature of the new digital "vanguard forces of production", and further growth in DI production, which is inevitable, will help to push the already precarious system of value production ever closer to its breaking point. If that is on the horizon, it is a matter of urgency for revolutionary praxis to respond to this economic predicament.

But these weighty results are only as credible as is the proposition that DI is valueless. Thus it is important, for matters of both theory and practice, to accurately assess just how credible this proposition is.

\section{Unit Value vs. Total Value}

In a lengthier statement about the root cause of Dl's lack of value, Rigi gives an example to elucidate his rationale:

According to Marx's theory of value, the value of information tends to zero. The reason for this is that information can be reproduced at almost zero cost. [...] For example, if the labour time that is required for writing software is 100 hours and the time required for copying it is five minutes, its value is determined by [a] 5-minute labour time, which is negligible. The reason for this is that the value of a commodity is determined by the socially necessary labour time for its reproduction. In the case of information this time is the socially necessary time for copying it [...] Thus in the case of our software the 5-minute copying time determines the social labour necessary for the production of software, not the initial 100 hours spent on the production of the first original copy. (2014a, 911-12)

This example makes it explicit that Rigi's contentions concern the unit value, rather than the total value, of what results from DI production.

\section{1. "Negligible" Value}

Several aspects of Rigi's software example are problematic. To begin with, without some adjustment, the example doesn't yield the desired mathematical result. When Rigi says that "an item of [digital] information is infinitely replicable at negligible extra cost and therefore its value tends to zero" (2014a, 923) he seems to have in mind a situation in which:

- $X=$ number of digital replicas of a piece of software

- 100 = labour hours necessary for writing software 
- Limit as $X \rightarrow$ infinity of $(100 / X)=0=$ unit value (in labour hours) of each digital replica

The problem with this is that Rigi builds into his example a copying time of five minutes $(=.083$ hours $)$, which he construes as a value-determining expenditure of labour power. So the proper formalism for the example is instead:

- Limit as $X \rightarrow$ infinity of $[(0100+.083 X) / X]=.083=$ unit value (in labour hours) of each digital replica.

This being the case, it is flatly incorrect to claim that, in the example as given, the value of a unit of information, measured in hours of labour, "tends toward 0 ." It tends toward five minutes (or the monetary equivalent thereof).

Rigi concedes this, evidently without realising it is a concession, when he says that the value of a unit of software "is determined by 5-minute labour time, which is negligible" (2014a, 912; emphasis mine). We can surmise that he means that five minutes of labour time is such a small amount that, for all value-theoretic intents and purposes, we can treat it as zero. But this is odd. Suppose we conservatively estimate the monetary expression of labour time (MELT) - the quantity of money that represents the value created by one hour of labour performed at the socially average level of intensity and proficiency - to be US\$20. In that case, five minutes of labour is represented by US\$1.66. At the time of writing this, that is almost exactly the cost of a box of Kleenex, which is nothing to sneeze at. Jokes aside, if Rigi is prepared to concede at the outset that DI production is roughly as value-productive as the production of facial tissue (which we have no reason to suppose to be valueless), he cannot consistently take the stance that DI is intrinsically valueless. Some simple arithmetic shows how little sense it makes to treat five minutes as "negligible" in the sense of 'practically speaking, zero': a piece of software that is downloaded a million times would, by Rigi's logic, yield an output embodying five million labour minutes, the labour-equivalent of US\$1.66 million (assuming a MELT of US\$20).

\subsection{The Irrelevance of Unit Value}

To be as charitable as possible to Rigi's arguments, let's amend his example so that the unit value of the software does tend toward 0 . The way to do this, within the schema Rigi has set up, is to assume (per impossibile) that it takes 0 minutes to copy the software. With this tweak to the model, the unit value gets closer and closer to zero, rather than closer and closer to five minutes, the more replicas are made. Are we now entitled to conclude all value has gone out the window?

No. The value of the unit commodity is a red herring in an investigation of whether a labour process produces value or not, because the unit value, considered apart from the number of units produced, is a useless piece of information. The value of the unit commodity is derived by dividing the total amount of value produced by the number of physical use-values created. Unit value will thus depend on a designation of what counts as a unit, which might be more or less arbitrary. When I purchase Jack Daniels at the corner liquor store, what is the relevant unit of whiskey, the gallon or the fluid ounce? An ounce has a value that is more "negligible" than that of a gallon, according to Rigi's reasoning, but this has no bearing on the total value of the total amount of whiskey. Plainly, what is relevant is the unit cost multiplied by the number of units. This is to say that the amount of new value produced and old value transferred, i.e. the 
amount of living labour set in motion by wage payments and the amount of dead labour stored up in the means of production, is logically and explanatorily prior to the way the resultant quantum of value is divided across a mass of individuated use-values.

In this vein, we also need to keep in mind that the claim that the value of a unit of information "tends to zero" $(2014 a, 911)$ is importantly different from the claim that "the value of the sold information is zero" $(2014 a, 926)$, even though Rigi treats these as the same. Obviously, a large number of units of a commodity whose value "is almost zero" $(2014 a, 911)$ could collectively be worth a lot; but a large number of units of an absolutely valueless commodity would still be absolutely valueless in the aggregate. Furthermore, although the limit as $X \rightarrow$ infinity of $(100 / X)=0$, in actuality, the unit of software will not have an infinitesimal value, because the number of replicas made will not "approach infinity" (whatever that might mean); it will always end up being a finite positive number which, when multiplied by the unit value, will yield another positive number (representing total value) that is greater than the unit value. Rigi's whole case, then, may hinge on the terminological bait-and-switch of using "zero" and "almost zero" interchangeably.

Observations similar to mine are made by Carchedi (2014), who identifies three sources of the value of a "product of mental labour" such as DI:

First of all [there is] the capital invested in the prototype. This is not only fixed constant capital (computers, premises, facilities...etc.). It is also circulating constant capital (raw materials [such as electricity]) and variable capital, wages, which go from very high (for highly qualified developers) to low [...] Let us call all these costs (a) [...]The other element is the additional capital invested in the production of the replicas of the prototype [...] Let us call these costs (b). The total capital invested is thus (a) plus (b) [...T]he total value of the replicas can be high. It is given by (a) plus (b), plus (c), i.e. the surplus value generated [...] The unit value is then given by the total value divided by the number of replicas made. It is directly proportional to the total value and inversely proportional to the quantity of the replicas $(2014,4-5) .^{3}$

Carchedi goes on to affirm the view that unit value is not determinative of, but is instead partially determined by, the amount of value produced (the other determining factor being quantity of replicas):

If [copy and sale of DI] stops when the receipts are less than the capital invested a loss is suffered. If production continues after that point, the profits made are the realization of the surplus value produced. If production continues further, the increased profitability derives from appropriation rather than production of surplus value [...] As far as costs of type (a) are concerned, the [more units are copied and sold], the lower the unit value but the higher the extra surplus value appropriated (Carchedi 2014, 5).

If costs of type (b) are zero, extra production of replicas of a prototype requires no labour or raw materials, and thus neither creates nor transfers any value, and thus has

${ }^{3}$ The Carchedi quotations are taken from an earlier draft of Carchedi (2014), which goes into slightly more detail on points relevant to my arguments. Page references are to a Word document of the draft that can be downloaded at http://marx2010.weebly.com/uploads/5/4/4/8/5448228/old wine new bottles the internet.docx. 
the effect of bringing unit value closer and closer to $0 .{ }^{4}$ But labourless/costless replication does not retroactively nullify the value transferred and created by the constant and variable capital corresponding to costs of type (a). These costs, particularly those that go into the labour-intensive (and to that extent highly valueproductive) development process, can be considerable. Smartphone apps, which have no physical shell and a purely digital existence, are a case in point: "The median price to create an app by expert agencies [in 2017] is $\$ 171,450$, according to a Clutch survey. Online app cost calculators name a price tag between $\$ 200,000$ and $\$ 350,000$ for an app with dozens of features, while typical cost range stated by app development companies is $\$ 100,000-\$ 500,000 "$ (Think Mobiles 2018).

\subsection{A Tendential Unit Value of Zero Presupposes a Non-0 Total Value}

We have seen that unit value does not tell the whole story. On top of this, not only does a tendential unit value of zero not imply a total value of zero; quite the contrary, it implies that value production took place and created a positive magnitude of value. This is because the exponential decay of unit value in Rigi's model must be understood as happening when the number of units continuously increases while the amount of value antecedently created is held constant. Put differently, without there having been a round of value-generating production in the first place, the value of the DI unit would just be zero, full-stop; there would be no reason for Rigi to appeal to an asymptotic approach to zero. In attempting to prove that DI is valueless by postulating decay toward a limit of 0 for unit value, Rigi unintentionally commits himself to the view that DI production creates value.

Although Rigi treats the tendential unit cost of zero as a special and highly consequential feature of $\mathrm{DI}$, the circumstances that give rise to this attribute - constant increase in total output of units in conjunction with total value being held constant - is not unique to DI. It is a feature of all 'nonrival' goods and other goods that can be produced at zero marginal cost. A good is nonrival when one party can consume it without thereby preventing its consumption by another party. This means it costs no more (or negligibly more) to provide it to the $n+1^{\text {th }}$ consumer than it does to the $n^{\text {th }}$ consumer. Roads and amusement parks are like this. Some rivalrous goods also have zero (or close to zero) marginal cost. An extra watt of solar power costs essentially nothing to generate, but it is rivalrous, since if I use the wattage, you can't also use that same wattage. Plainly, the initial outlay (the requisite constant and variable capital) for constructing amusement parks and solar power plants, unlike the marginal cost of providing amusing experiences and electricity, is non-negligible, and the construction process that gets things up and running requires variable capital that can generate value and surplus value.

${ }^{4}$ Of course, the same basic thing happens when the digital information is encoded in a physical shell such as a DVD. The more DVDs of a video game are produced, the closer the game's unit value gets to the value of the blank DVD alone. But, in like manner, this in no way retroactively diminishes the value created by the productive labour of development. The development of the video game Grand Theft Auto V took five years, involved a 1000-person development team, and cost an estimated US\$137 million (Wikipedia 2019). The value-producing capacity of this development labour is not somehow subverted by the fact that the retail cost of a blank DVD is less than US\$0.20. Incidentally, given a MELT of $\$ 20$, a blank DVD worth US\$.20 represents 36 seconds of labour time, far less than the "five-minute labour time" Rigi estimates for digital replication. The example of Grand Theft Auto V was brought to my attention by Jarek Ervin. 
As an illustration of the same point, take the case of a musical performance, in a ticketed concert venue, for which admission is charged. ${ }^{5}$ The per-unit commodity value (not to be confused with the actual price of a ticket, which is another matter) decreases as the number of audience members increases. This is because what counts as a unit of this commodity is the act of witnessing the performance. The more spectators there are, the greater is the denominator that divides the (unchanging) numerator that stands for the labour time socially necessary for staging the performance. Other things being equal, the total value of the performance is given by the undivided numerator (some proportion of which may be surplus value). For, again, what matters is not the marginal socially necessary labour time required to produce another commodity unit (by, in this case, admitting an additional audience member). Rather, what matters is all the labour, dead and living, that went into preparing and executing the musical performance. From Rigi's avowedly Marxian standpoint, there is no reason to deny a priori that the nondisaggregated commodity mass - the whole performance, as an event - which can be, but needn't be (for value-theoretic purposes), analytically decomposed into discrete commodity units (individual instances of viewing), possesses a value that straightforwardly corresponds to the number of socially necessary labour hours that enter into its production and distribution as either materials or labour $(c+v)$. This magnitude of value is determined prior to, and is not raised or lowered by, the number of discrete units over which it ends up getting apportioned.

Now take the same scenario and adjust it so that the musical performance is also offered as a pay-per-view broadcast that gets digitally transmitted. With continuous increase in the number of digital transmissions (each of which requires zero or negligible further cost/labour time), the value of each unit commodity (each act of witnessing the performance) gets closer to zero. Conceptually speaking, this is like changing the original example by magically endowing the performance venue with an infinite physical capacity, so that any number of audience members can partake of the live viewing experience (making it a fully nonrival commodity, rather than nonrival only up to the capacity of the arena). But this adjustment to the thought experiment does not introduce any new considerations that should make us think that the whole affair is all of a sudden no longer generative of value or surplus value. The only difference is that now the denominator (number of units) has no pre-ordained upper bound. But, to reiterate, all the matters for the calculation of value is the numerator (the total value magnitude).

\section{Production and Reproduction}

Rigi's explanation of the alleged valuelessness of DI is premised upon on three key notions: (1) that reproduction time determines commodity value; (2) that the reproduction of DI consists in its being copied/transferred; and (3) that copying/transferring DI takes very little, or practically zero, time/cost/labour. From this it is supposed to follow that DI has no value. So far, I have raised these challenges: (1) Rigi's proposed model, as originally described, does not involve an asymptotic

\footnotetext{
${ }^{5}$ Marx is in no doubt about whether musical performances can produce value: "A singer who sings like a bird is an unproductive worker. If she sells her singing for money, she is to that extent a wage labourer or a commodity dealer. But the same singer, when engaged by an entrepreneur who has her sing in order to make money, is a productive worker, for she directly produces capital. A schoolmaster who educates others is not a productive worker. But a schoolmaster who is engaged as a wage labourer in an institution along with others, in order through his labour to valorise the money of the entrepreneur of the knowledge-mongering institution, is a productive worker" (Marx 2010, 136).
} 
approach to zero; (2) Rigi has an eccentric interpretation of the meaning of "negligible value"; (3) the most Rigi has shown (if his example is charitably corrected) is that a unit of DI can conceivably have a tendential value of zero, which does not imply zero total value for an entire batch of units; (4) it is a mistake to equate very low unit value with zero unit value; and (5) a tendential unit value of zero presupposes a non-zero, positive total value.

I want now to turn to the topic of reproduction. What, for a Marxian economist, is reproduction as opposed to production? To say that reproduction time, rather than production time, determines commodity value is to say that a given commodity, no matter when it was produced and no matter what level of productivity it was originally produced at, de facto contains whatever amount of value is contained by the same type of commodity produced at the current prevailing average level of productivity. As Rigi writes:

[T]he average social productivity of all producers determines the amount of socially necessary labour time that congeals as value in the product. In order to produce cheaper, and thereby acquire a greater share of the market, individual capitalists increase the labour productivity of their own enterprises. This in its turn leads to the growth of the average social productivity of all enterprises that produce a certain commodity. As a result the socially necessary labour time for the production of the commodity, and thereby its value, decreases. If there is a stock of a commodity previously produced under a lower labour productivity, its value depreciates. Now, it has a value as if it has been reproduced under the new higher labour productivity. (Rigi 2014a, 912)

Hence 'reproduction' of a commodity, in the Marxian scheme, refers to the production of that commodity in the most recent production cycle. Rigi maintains that, since reproduction of DI consists in its being copied/transferred, the amount of socially necessary labour time it most recently took for the copying/transferring of a piece of DI is what establishes the current prevailing average level of productivity for the $\mathrm{DI}$, and is thus what establishes the value of that type of DI. Copying and transferring files, according to this explanation, reproduces DI commodities in the sense that the copy/transfer process is what is responsible for bringing new units of that commoditytype into existence. Notwithstanding the use of terms like "immaterial" and "nonphysical" in connection with DI, what happens in the copy/transfer process needn't be conceived of as somehow spooky or incorporeal: buying and downloading software amounts to paying to have a computer put in a different physical state, viz. whatever configuration of silicon and electrons (etc.) allows it to successfully run the program. (With that in mind, I would note as an aside, we may be tempted to characterise what's going on in file transfer as the performance of a service rather than the creation of an enduring, though immaterial, commodity-object - the copy or replica of a piece of software - that is numerically distinct from other instances of the same type of object.)

\subsection{Intellectual Property and Zero Value}

Rigi holds that in order for DI to command a price, it must be made artificially scarce via intellectual property (IP) protection - trademark, copyright, and patent law.

This is supposed to demonstrate that, like land, DI is intrinsically valueless, such that profits derived from the sale of $\mathrm{DI}$, like those derived from leasing land, are rent: 
In contrast to the natural scarcity of land, intellectual property is artificially made scarce by the force of the lawstate. Hence, the arbitrariness of intellectual property is far more obvious and less naturalised than that of landed property. Thus, information rent more explicitly takes the form of tribute than ground rent does so, therefore, we can call it information rent-tribute (2014a, 924).

To be sure, once information assumes a digital form, it is technologically feasible for it to be universally distributed with negligible effort/time/cost. And without IP, DI would be non-excludable: it would not be possible to prevent non-paying consumers from having access to it, it would not be subject to the law of scarcity, it could not function as a commodity, and it could not behave in the market economy as a bearer of exchange value. But all that this indicates is that, counterfactually, DI would be devoid of value (since it could not command a price and would not be saleable) if there were no IP. It does not show that, in actuality, it is valueless within the context of the regnant IP regime. To appreciate this, consider once more the example of the musical performance. Here is a (pretty much) true counterfactual conditional: if there were no longer any artificial barriers (such as laws and gates and security guards) preventing people from wandering into auditoriums to listen to music without paying, it would then be the case that concert tickets couldn't command a price, and musical performances couldn't be used to produce value (as Marx thinks they can be). But what does this hypothetical tell us about the value of musical performances in the real capitalist world, with its multifarious devices and conventions for privatisation and enclosure? Precisely nothing. Far from serving as evidence of valuelessness, artificial barriers to access are a sine qua non for the musical performance to retain its price tag and for capitalist impresarios to realise surplus value. Likewise for IP and DI.

The crux of this is that Marx's notion of reproduction has to do with actualities, not possibilities. Stored-up, unsold commodities have a value that is determined by the most recent actual process of production, not by possible but non-actual states of affairs (such as the abolishment of intellectual property) that might someday obtain. By identifying reproduction, as opposed to production, as the real determinant of value, Marx is asserting that the labour time it most recently took to produce a batch of commodity units determines the amount of value contained in all commodity units of that type that are currently in stock, which may have been made at a lower level of productivity (with higher input costs and / or more labor). The amount of value contained in these older commodities is reduced upon the provision of the new batch of cheaper articles. Marx says:

Apart from all accidental circumstances, a large part of the existing capital is always being more or less devalued in the course of the reproduction process, since the value of commodities is determined not by the labour-time originally taken by their production, but rather by the labour-time that their reproduction takes, and this steadily decreases as the social productivity of labour develops. At a higher level of development of social productivity, therefore, all existing capital, instead of appearing as the result of a long process of capital accumulation, appears as the result of a relatively short reproduction period $(1981,522)$.

Since Marx uses the present tense to tell us that it is "in the course of the reproduction process" (im Lauf des Reproduktionsprozesses) that existing capital "is always being more or less devalued" (wird beständig mehr oder weniger entwertet), we can infer that he means that it is actual current reproduction (which, in our day and age, includes the increasingly byzantine and draconian legal framework of IP) not possible future 
reproduction (in, say, an open-access utopia) that determines the value of commodities, digital or otherwise.

\subsection{Is Digital Copying Reproduction?}

The Lauf des Reproduktionsprozesses takes place fully within the circuit of capital accumulation: it is production by wage labourers for capitalists. Reproduction of a piece of software, in the sense Marx intends, would have to mean the most recent round of production of the software, by a capitalist enterprise, for the market, at the up-to-date level of efficiency.

When a digital copy of Microsoft Office is transferred to someone's computer, is that, all by itself, something Marx would want to call 'reproduction'? I'll assume that the digital copy/transfer of Microsoft Office can take place in one of two main ways (ignoring variations that might involve institutional intermediaries other than Microsoft): (1) Microsoft Corporation makes Office available to a customer, who pays to download it; or (2) the software is illegally pirated by someone who doesn't pay for it.

The second case is not a case of capitalist production at all and therefore not a case of reproduction. This is not to say that theft can't influence price. The stealing of goods introduces an inefficiency into distribution that could be reflected in higher commodity prices because of lost inventory, expensive security measures, and so on. And widespread or universal theft of a certain kind of object would effectively decommodify it and nullify its value-bearing capacity. But this is orthogonal to the very different issue of how maximally efficient (zero-marginal cost) reproduction brings unit value closer to zero. Reproductive labour is labour that goes into producing in order to sell, not labour that goes into stealing in order to possess. ${ }^{6}$

Now consider the other alternative, where Microsoft Corporation authorises the transfer of a digital replica of its software to the computer of a paying customer. Intuitively, it is more natural to describe this as an act of distribution instead of an act of production. ${ }^{7}$ In transferring the Office file and granting the file's recipient legal entitlement to use it, Microsoft is engaging in what looks like the circulation of an already-produced good, albeit a good of which the firm has a functionally limitless supply, and moreover a good whose circulation does not require the literal spatial relocation of a persisting spatiotemporal object.

An authentic reproduction process for Microsoft-Office-type software, as opposed to a distribution process, would involve a capitalist firm undertaking a productive cycle that would enable the firm to supply consumers with a commodity sufficiently similar to Office so as to be substitutable for it and thus in competition with it. As Carchedi says, this endeavour would involve "not only fixed constant capital (computers, premises, facilities...etc.) [...but] also circulating constant capital (raw materials [such as electricity]) and variable capital, wages, which go from very high (for highly qualified developers) to low" $(2014,5)$. Microsoft Corporation obviously does not need to initiate any such process, since it is not in competition with itself and is already in a position

\footnotetext{
${ }^{6}$ Marx, quoting Adam Smith, makes a sarcastic remark about thieving that is intended to make precisely the same point: "The thief, too, who pays himself - just as the law-courts and the State do - 'employs his energy, uses it in a particular way, produces a result which satisfies a human need,' i.e., the need of the thief and perhaps also that of his wife and children. Consequently [he is a] productive labourer if it is merely a question of producing a 'result' which satisfies a 'need,' or as in the cases mentioned above, if selling his 'services' is enough to make them 'productive"' (Marx 1969, 293).

${ }^{7}$ Marx does believe that some of the labour of distribution, such as moving goods from place to place, is partially constitutive of use-value creation and is thus productive labour.
} 
to supply consumers from its (functionally limitless) digital 'stock' of Office replicas. ${ }^{8} \mathrm{~A}$ competing firm, though, would need to incur expenses of the sort enumerated by Carchedi if it wished to bring to bring a comparable digital commodity to market, and this reproductive process would entail the kind of research and development, code writing, and so forth, that went into Microsoft's initial round of software production. But it goes without saying that the competitor's reproduction process takes more than a negligible amount of labour. ${ }^{9}$

In short: of the two cases under scrutiny - pirating Office and reproducing it in the authentic Marxian sense - the former case is not reproduction and the latter case requires a significant amount of labour, and hence in no way motivates the conclusion that DI is valueless.

\section{Conclusion}

Inarguably, capitalist firms that produce DI sometimes receive more profit than corresponds to amount of surplus labour they preside over. The graphics design, sound production and software development for the game Candy Crush is estimated to have cost between US $\$ 90,000$ and US $\$ 110,000$ (Klubnikin 2017); whereas, as of the end of 2018, gross revenue for sales of the game exceeded US\$5 billion (Video Game Sales Wiki 2019). Clearly, the value of Candy Crush stands well below the amount of income it has yielded. But there is nothing novel or paradigm-shifting about this. Superprofits can be secured by any highly efficient or monopolistic firm, irrespective of whether its products are immaterial or instead fully corporeal and tangible. Whether or not a firm that sells digital commodities is the recipient of superprofits is not a question we will be able to settle from the armchair by pondering the 'immaterial' ontology of DI or by imagining fictional states of affairs such as the abolishment of IP. There is no royal road from metaphysics and counterfactuals to the conclusions that DI is valueless and that the sale of information is rent extraction. Instead, questions about the value of DI can only be settled by empirical data: we need to know things like what firms' input costs are, how much labour they employ, and how many units they sell, so that we can make principled conjectures about how many hours of socially necessary labour time they command and about the per-unit and total value of their commodity output.

\section{References}

Carchedi, Guglielmo. 2014. Old Wine, New Bottles, and the Internet. Work Organisation, Labour and Globalisation 8 (1): 69-87.

Hardt, Michael and Antonio Negri. 2009. Commonwealth. Cambridge, MA: Harvard University Press.

Hardt, Michael and Antonio Negri. 2004. Multitude. London: Penguin Books.

8 Here I ignore complicated considerations involving planned obsolescence and the introduction of new editions of the same software - e.g. successive iterations of Microsoft Windows - that replace earlier versions without fully rendering them obsolete. I am grateful to Jarek Ervin for raising this issue in conversation.

9 The competitor's reproduction process might take much less time than Microsoft's original production process, perhaps if some of Microsoft's more difficult creative work in development (figuring out the basic type of software platform that would appeal to consumers, or whatever) didn't need to be repeated. This might allow the new software to be profitably sold at a lower price, which would devalue Microsoft's existing "stock." That would be a genuine instance of reproduction reducing stored value. 
Klubnikin, Andrei. 2017. How Much Does a Game Like Candy Crush Cost? R-Style Lab [Blog]. Accessed January 1, 2019. https://r-stylelab.com/company/blog/mobiletechnologies/how-much-does-a-game-like-candy-crush-cost

Marx, Karl. 2010. Results of the Direct Production Process. In Marx and Engels Collected Works Vol. 34, translated by Ben Fowkes, 355-466. London: Lawrence and Wishart.

Marx, Karl. 1981. Capital: A Critique of Political Economy Vol. 3. Translated by David Fernbach. London: Penguin.

Marx, Karl. 1976. Capital: A Critique of Political Economy Vol. 1. Translated by Ben Fowkes. London: Penguin.

Marx, Karl. 1969. Theories of Surplus Value Part I. Moscow: Progress Publishers.

Rigi, Jakob. 2015. The Demise of the Marxian Law of Value? A Critique of Michael Hardt and Antonio Negri. In Reconsidering Value and Labour in the Digital Age, edited by Eran Fisher and Christian Fuchs, 188-206. New York: Palgrave Macmillan.

Rigi, Jakob. 2014a. Foundations of a Marxist Theory of the Political Economy of Information: Trade Secrets and Intellectual Property, and the Production of Relative Surplus Value and the Extraction of Rent-Tribute. tripleC: Communication, Capitalism \& Critique. Open Access Journal for a Global Sustainable Information Society 12 (2): 909-936. Accessed February 6, 2019. https://www.triple-c.at/index.php/tripleC/article/view/487

Rigi, Jakob. 2014b. The Coming Revolution of Peer Production and Revolutionary Cooperatives: A Response to Michel Bauwens, Vasilis Kostakis and Stefan Meretz. tripleC: Communication, Capitalism \& Critique. Open Access Journal for a Global Sustainable Information Society 12 (1): 390-404. Accessed February 6, 2019. https://www.triple-c.at/index.php/tripleC/article/view/486

Rigi, Jakob. 2013. Peer production and Marxian Communism: Contours of a New Emerging Mode of Production. Capital and Class 37 (3): 497-416. Accessed February 6, 2019. https://journals.sagepub.com/doi/pdf/10.1177/0309816813503979?casa token=Xiajl8qFX E0AAAAA\%3ATm5d5E6FyWeO-pZA-iYld2gU8QJTw3KLTArKUFo0GkT3ufl4ZatGxzXI9EmnajSApPsCoBS59gxUQ

Rigi, Jakob. 2012. Peer Production as an Alternative to Capitalism: A New Communist Horizon. Journal of Peer Production 1. Accessed February 6, 2019. http://peerproduction.net/issues/issue-1/invited-comments/a-new-communist-horizon/

Rigi, Jakob and Robert Prey. 2015. Value, Rent, and the Political Economy of Social Media. The Information Society 31:5. 392-406.

Think Mobiles [Blog]. April 2018. How Much Does it Cost to Make an App? Accessed January 28, 2019. https://thinkmobiles.com/blog/how-much-cost-make-app/

Video Game Sales Wiki. 2019. Accessed January 29, 2019. https://vgsales.fandom.com/wiki/List of highest-grossing video games\#cite ref-53.

Wikipedia. Development of Grand Theft Auto V. Accessed January 28, 2019. https://en.wikipedia.org/wiki/Development of Grand Theft Auto V

\section{About the Author}

Bryan J. Parkhurst

Bryan Parkhurst is an assistant professor of philosophy and music at Oberlin College. 